\title{
Accident frequency and unrealistic optimism: children's assessment of risk
}

Mary Sissons JOSHI ${ }^{\mathrm{a}^{*}}$, Morag MACLEAN ${ }^{\mathrm{a}} \&$ Claire STEVENS $^{\mathrm{b}}$

*Corresponding author:

Dr Mary Joshi,

Department of Psychology, Health and Professional Development, Faculty of Health \& Life Sciences,

Oxford Brookes University, Gipsy Lane, Oxford OX3 0BP, UK

e-mail: msissons-joshi@brookes.ac.uk.

\footnotetext{
a Department of Psychology, Health and Professional Development, Faculty of Health \& Life Sciences, Oxford Brookes University, Gipsy Lane, Oxford OX3 0BP, UK e-mail: mmaclean@brookes.ac.uk

${ }^{\mathrm{b}}$ Research Department of Behavioural Science and Health, UCL Institute of Epidemiology and Health Care, London WC1E 6BT, UK email: claire.stevens.14@ucl.ac.uk
} 


\title{
Accident frequency and unrealistic optimism: children's assessment of risk
}

\begin{abstract}
Accidental injury is a major cause of mortality and morbidity among children, warranting research on their risk perceptions. Three hundred and seven children aged 10-11 years assessed the frequency, danger and personal risk likelihood of 8 accidents. Two socialcognitive biases were manifested. The frequency of rare accidents (e.g. drowning) was overestimated, and the frequency of common accidents (e.g. bike accidents) underestimated; and the majority of children showed unrealistic optimism tending to see themselves as less likely to suffer these accidents in comparison to their peers, offering superior skills or parental control of the environment as an explanation. In the case of pedestrian accidents, children recognised their seriousness, underestimated the frequency of this risk and regarded their own road crossing skill as protection. These findings highlight the challenging task facing safety educators who, when teaching conventional safety knowledge and routines, also need to alert children to the danger of over-confidence without disabling them though fear.
\end{abstract}

Keywords: primary school-age children, unrealistic optimism, risk perception, accidents, pedestrian 


\section{Accident frequency and unrealistic optimism: children's assessment of risk}

\section{Introduction}

Accidental injury is a major cause of mortality and morbidity, particularly among children and young people (Public Health England, 2014; Towner et al, 2005; WHO, 2008). In the UK in 2011, 165 children aged under 15 died as a result of unintentional injury, and annually one child in five attends an Accident and Emergency (A \& E) department (Miskin, 2013). Injury is not only costly to individuals and families but places a burden on the state (Lyons et al, 2011) as even a single visit to A \& E in the UK involving no treatment costs the state $£ 138$ (Department of Health, 2016).

Traffic accidents are a major cause of serious injury and death for children and are ranked as the second most frequent cause of death to 10-14 year olds world-wide (WHO, 2008). Notwithstanding the roles of enforcement such as $20 \mathrm{mph}$ zones and other traffic calming measures, education has always been regarded as an important component of injury minimisation and prevention strategies. Schools and safety centres commonly focus on skills such as road crossing codes, which list procedures to be followed for safe navigation of the environment (Lamb et al., 2006; Schwebel et al., 2012; Schwebel et al., 2016).

Cognitive psychologists, however, have highlighted some of the barriers to effective use of these procedures. For example, children's ability to cross a busy road safely is hampered by their inability to assess the speed of approaching vehicles (Wann et al., 2011). Further difficulties may arise from inappropriate assessment of the probability or severity of various accidents (Weinstein, 2000). Research with adults has shown that people tend to be over concerned with rare and 'dreaded' hazards (such as nuclear weapons accidents) at the expense of the more common and 'mundane' (such as auto accidents) (Slovic, 1987). 
Adult respondents tend to over-estimate the frequency of death from rare causes, such as botulism or tornado, while under-estimating the frequency of death from common causes such stroke and heart disease (Lichtenstein et al., 1978) with the possible consequence that people underestimate the importance of the behaviour change required in respect of common but serious illnesses and hazards (Sheeran et al., 2013). One explanation of this bias is that the frequency of rare risks is over-estimated as instances easily come to mind (i.e. they are subject to the 'availability heuristic', Tversky \& Kahneman; 1973) due in part to dramatic media coverage.

Another bias which has been demonstrated to lessen people's appreciation of risk is unrealistic optimism, i.e. the tendency for people to think that risks, including accidents, apply more to other people than to themselves (Shepperd et al., 2013; White et al., 2011). Some research suggests that children are also susceptible to unrealistic optimism (Whalen et al., 1994), although little of this research has looked at unrealistic optimism concerning accidents.

This study seeks to investigate the underestimation and optimism biases in 10-11 year old children with respect to accidents as these biases, if present, are likely to impact on children's execution of safety procedures. To our knowledge estimation (as assessed by Lichtenstein et al, 1978) and the Tversky \& Kahneman (1973) approach to availability have not been investigated in children. While children of this age group are able to use statistical information to make social judgements and this increases in childhood (Jacobs \& Klaczyski, 2002) it remains an open question whether children show the same biases as adults (Schlottmann \& Wilkening, 2012). This age group (10-11 year olds) was also chosen as this is when UK children are about to leave primary school and are likely to begin to walk or cycle unaccompanied to school and other destinations (Shaw et al, 2013), and is just prior to the age (12 years) when pedestrians are at most risk of accident (PACTS, 2013). 


\section{Method}

\subsection{Participants}

Primary schools in Oxfordshire, UK were contacted and 19/47 agreed to take part in the research. All children $(\mathrm{N}=341)$ for whom parents gave consent $(73 \%)$ were invited to take part. The analysis is based on 307 Year 6 children (143 boys and 164 girls, aged 10-11 years) $(34 / 341$ children were not at school on the day of the study). See Supplementary Material available online for sample size calculation. The study was approved by the Oxford Brookes University Research Ethics Committee.

\subsection{Procedure and stimuli}

A one-to-one interview session opened with children looking at a series of commissioned cartoons depicting a day in the life of a 10 year old child which involved a variety of activities including potential hazards on the road, in school, and at home. This primed the children to think about risk. Eight specially drawn colour images on separate cards depicting accidents 'about to happen' were then presented to the children (see Figure 1). 


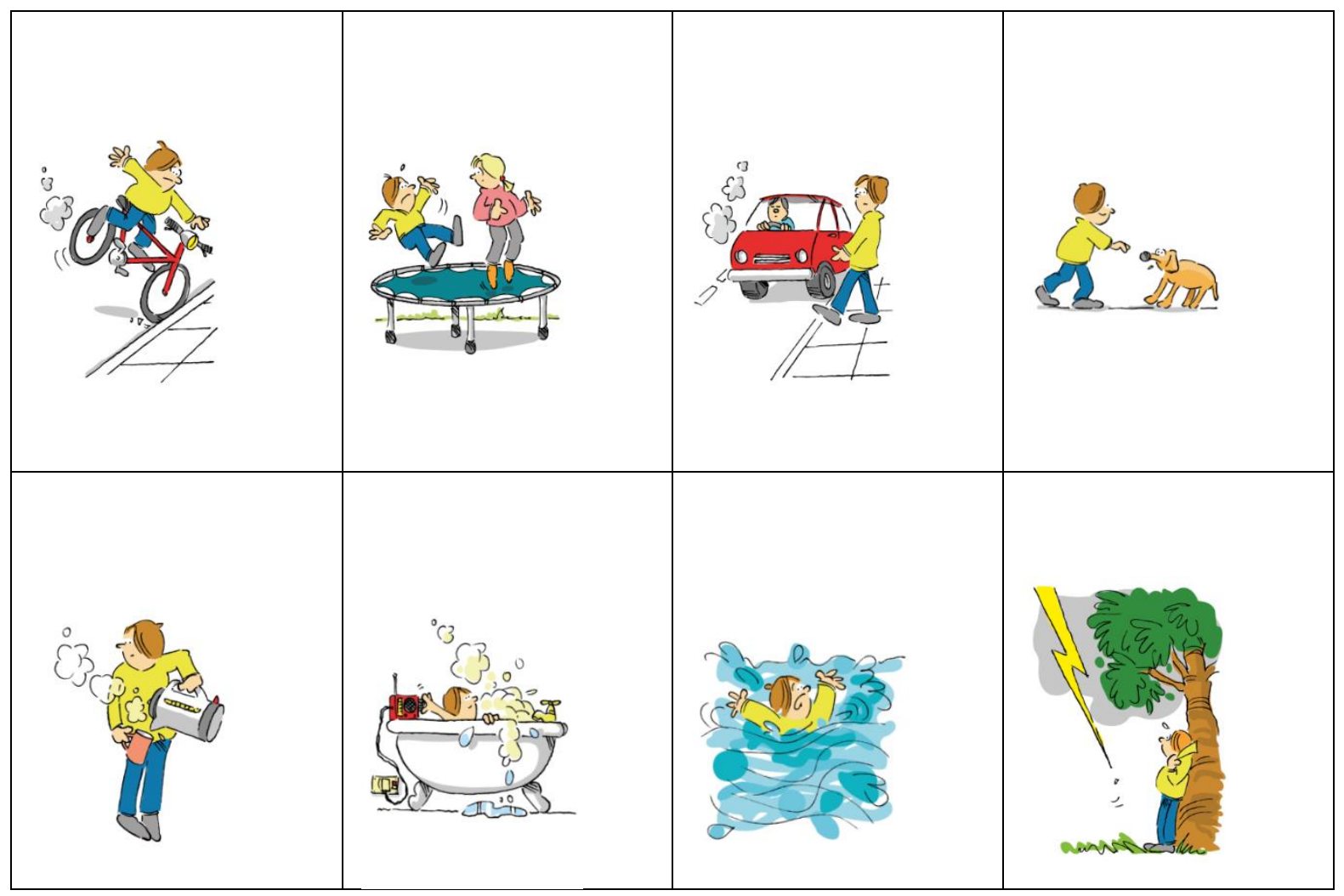

Figure 1: Images depicting accidents 'about to happen’

These showed a sample of risks/hazards of varying frequencies which together constitute $21 \%$ of admissions to hospital via A\& E for those aged $10-14$ years, according to Public Health England Hospital Episode Statistics. The pictures were accompanied by a series of questions designed to measure children's judgements about danger, frequency, and personal risk / unrealistic optimism. The eight pictures were given to the children in random order and they were asked to identify the nature of the 'accident about to happen' before making a series of judgements described below.

\subsubsection{Danger judgement}

The children ranked the images by how dangerous and harmful such an accident would be. This measure was designed to capture Slovic's (1987) notion of 'dreaded' risks. 


\subsubsection{Frequency judgement I}

The children ranked the same images for frequency, i.e. assessing how often these accidents happen to children their age.

\subsubsection{Frequency judgement II}

A second measure of frequency (designed to allow the expression of absolute rather than ranked frequency) required the children to imagine that they were a doctor who comes to work after a few weeks holiday to find that 50 children aged around 10-11 years had been admitted to the hospital with sufficiently bad injuries that they need to stay in hospital for a while. The children were asked to allocate cut-outs of people to the images (still in the order previously sorted by them for frequency) to show how many of the 50 children have had each kind of accident. If a child asked whether each accident had to have some admissions, they were told that it was OK for some accidents to have no admissions. The development of this measure is described in the Supplementary Material.

\subsubsection{Personal risk/Unrealistic optimism}

Children were asked to decide for each of the eight accidents whether there was less, more, or the same chance of this accident happening to them in comparison to other children of their age (Shepperd et al., 2015). On every occasion that a child responded with 'less likely' they were asked to give their reasoning. The explanations were categorised into references to protective factors such as their own skill or lack of exposure to the risk due, for example, to adult control of the situation.

\subsubsection{Risk availability}


For adults the traditional method for assessing 'availability' has involved media coverage (Lichtenstien et al, 1978). As this approach is not appropriate for use with children, we chose to instead to elicit which accidents the children in our sample viewed as 'sensational' (as a proxy for 'availability'). Each child was asked to nominate from among the eight accidents which one they would use if they had to write a 'very thrilling and exciting story' involving an accident. For full details of interview see Supplementary Material.

\section{Results}

\subsection{Danger}

Children rated pedestrian accidents more dangerous than any of the other accidents and significantly more dangerous than the two considered as the next most dangerous, namely drowning and being hit by lightning (as established by planned comparisons of means following analysis of variance, see Table $1, \mathrm{~F}=827.30$, df 7,299, $\mathrm{p}<.001, \eta^{2}=.951$ ). There was a trend towards accidents rated as more dangerous being judged as less frequent: $r(6)=$ $.66, p=.076$. The exception to the high danger/low frequency perception was pedestrian accidents which were seen as the most dangerous of all accidents, but ranked as of middle frequency.

\subsection{Children's judgement of frequency of different kinds of accident}

Children's 1-8 ranking of the frequency of the accidents approximated to actual hospital admissions: $r(6)=-.87, p=.005$. When asked to assess frequency by allocating the expected number of admissions of children their age to hospital via Accident and Emergency, 
the rank ordering showed similarly close correspondence with actual admissions: $r(6)=-.88$, $p=.004$. However, overall rank ordering does not reflect distance between scores and obscures the fact that if the scores are compared to each other individually the frequency of pedestrian accidents, dog bites and burns were judged to be similar both in terms of frequency rankings and imagined hospital admissions $\left(F=387.91\right.$, df 7,299, $p<001, \eta^{2}=.901$, see Table 1).

Table 1 also shows the differences between children's estimations of the proportion hospital admissions for each accident type $\left(F=150.75\right.$, df $\left.7,299, p<.001 \eta^{2}=.331\right)$. Although it could be thought that asking children to allocate counters to each of the eight accident types may have given children the impression that they had to allocate counters to each accident type, in fact $12 \%(36 / 307)$ of children allocated zero counters to one or more of the accident types. Each accident type was on occasion allocated zero counters - with this being most frequent in the case of being struck by lightning to which 30 children allocated zero counters (and the average number of counters in this case were 2.52 (sd 1.89) (i.e. $5 \%$ of the total), and the modal response was 1.0 , given by $81 / 307$ children) (i.e. $2 \%$ of the total), and least frequent in the case of bike accident where only one child allocated zero counters to this accident (with the average being 9.33 (sd 3.33) (i.e. 19\% of the total), and the modal response was 10 (i.e $20 \%$ of the total), given by $49 / 307$ children).

Children judge the frequency of burns, dog bites and pedestrian accidents to be similar in frequency using this different method of assessment. Figure 2 plots the actual proportional frequency of the eight accidents versus children's estimations of those accidents in absolute terms. The difference between real and perceived frequency was compared to zero using single sample t tests (see Table S2 in Supplementary Material). In each case the difference was significant, showing that the children over-estimated the occurrence of the 
five low frequency events and underestimated the occurrence of the three high frequency events. Dog bites, burns, electrical accidents, drowning and being hit by lightning were overestimated, on average, by $7.73 \%, 95 \% C I[7.63,8.08]$, while bike, trampoline and pedestrian accidents were underestimated, on average, by $12.88 \%, 95 \% C I[12.29,13.03]$ $($ paired $t(306)=67.85, p<.001, d=3.87)$, see Supplementary Material Table S2. 
Table 1 Risks: Danger and Frequency Judgements

\begin{tabular}{|c|c|c|c|c|c|c|c|c|c|}
\hline \multirow[t]{4}{*}{ Accident type } & & \multirow{2}{*}{\multicolumn{2}{|c|}{$\begin{array}{l}\text { Admissions to hospital } \\
\text { via } A \text { \& E }\end{array}$}} & \multicolumn{6}{|c|}{$\begin{array}{l}\text { As viewed by children } \\
\qquad \mathrm{N}=307\end{array}$} \\
\hline & & & & \multicolumn{2}{|c|}{ Danger } & \multicolumn{4}{|c|}{$\begin{array}{ll}\text { Frequency }\end{array}$} \\
\hline & \multirow[t]{2}{*}{$\begin{array}{c}\text { WHO } \\
\text { ICD-10 } \\
\text { Codes (causes) } \\
\end{array}$} & \multirow[t]{2}{*}{$\mathrm{N}$} & \multirow[t]{2}{*}{ As $\% *$} & \multicolumn{2}{|c|}{$\begin{array}{c}\text { Average rank } \\
\text { (low number }=\text { high } \\
\text { danger) }\end{array}$} & \multicolumn{2}{|c|}{$\begin{array}{c}\text { Average rank } \\
\text { (low number }=\text { high } \\
\text { frequency) }\end{array}$} & \multicolumn{2}{|c|}{$\begin{array}{l}\text { Perceived hospital } \\
\text { admissions }^{+}\end{array}$} \\
\hline & & & & Mean & $95 \% \mathrm{CI}$ & Mean & $95 \% \mathrm{CI}$ & Mean \% & $95 \% \mathrm{CI}$ \\
\hline Bike & V12-19 & 1645 & $37.10 \%$ & $5.50^{\mathrm{d}}$ & $5.33,5.66$ & $2.25^{\mathrm{a}}$ & $2.10,2.41$ & $19 \%^{\mathrm{a}}$ & $18,19 \%$ \\
\hline Trampoline & $\mathrm{W} 09^{* *}$ & 1291 & $29.12 \%$ & $6.68^{\mathrm{e}}$ & $6.54,6.81$ & $2.60^{b}$ & $2.42,2.78$ & $17 \%^{b}$ & $16,18 \%$ \\
\hline Pedestrian & V03-09 & 994 & $22.42 \%$ & $2.20^{\mathrm{a}}$ & $2.06,2.34$ & $4.06^{\mathrm{c}}$ & $3.82,4.29$ & $14 \%{ }^{\mathrm{c}}$ & $13,15 \%$ \\
\hline Dog bite & W54 & 323 & $7.28 \%$ & $6.95^{\mathrm{e}}$ & $6.81,7.10$ & $3.97^{\mathrm{c}}$ & $3.76,4.18$ & $13 \%{ }^{c}$ & $13,14 \%$ \\
\hline Burns & $\mathrm{X} 10-12,15,19$ & 150 & $3.38 \%$ & $5.58^{\mathrm{d}}$ & $5.40,5.75$ & $4.48^{\mathrm{c}}$ & $4.27,4.69$ & $13 \%^{\mathrm{c}}$ & $12,14 \%$ \\
\hline Electrical & W86, 87 & 16 & $0.36 \%$ & $3.53^{\mathrm{c}}$ & $3.35,3.71$ & $5.75^{\mathrm{d}}$ & $5.58,5.91$ & $9 \%{ }^{\mathrm{d}}$ & $9,10 \%$ \\
\hline Drowning & W69-74 & 13 & $0.29 \%$ & $2.82^{\mathrm{b}}$ & $2.66,3.00$ & $5.55^{\mathrm{d}}$ & $5.36,5.75$ & $10 \%^{\mathrm{d}}$ & $9,10 \%$ \\
\hline Lightning & X33 & 1 & $0.02 \%$ & $2.73^{b}$ & $2.55,2.93$ & $7.32^{\mathrm{e}}$ & $7.18,7.45$ & $5 \%{ }^{\mathrm{e}}$ & $4,5 \%$ \\
\hline
\end{tabular}

* $\quad$ As a $\%$ of those 8 accidents, as admitted via Accident \& Emergency, 2012/13, Aged 10-14 only, Hospital Episode Statistics $(\mathrm{N}=4433)$

(Total admissions via A \& E for this age group $=20,954$ - excluding self-harm, assault, sequelae of medical procedures.)

Cause codes of admissions via A \& E are used rather than codes at A \& E attendance as the latter are unreliable due to $35 \%$ or more of records having no codes. See http://www.hscic.gov.uk/catalogue/PUB19124.

** W09 refers to falls 'on or from playground equipment'. A recent local survey suggests these are predominantly trampoline injuries (Taylor, 2015).

$+\quad$ Vertical non-shared superscript indicates significant differences between values established via paired comparisons at $p<.01$ 


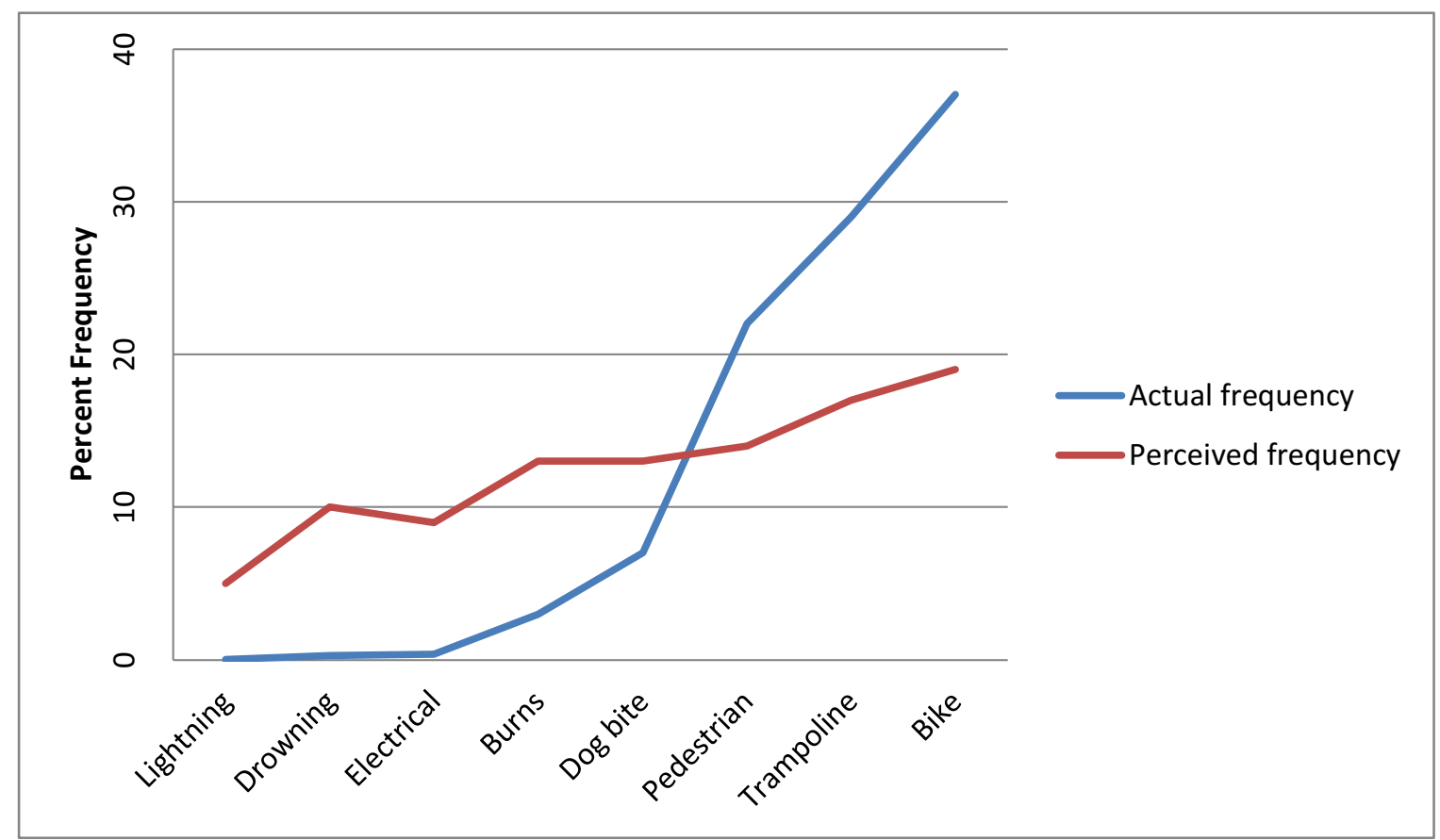

Figure 2 Actual and perceived frequency judgements by accident type

Table 2 Personal risk judgements

\begin{tabular}{|c|c|c|c|c|}
\hline \multirow[t]{2}{*}{ Accident type } & \multicolumn{4}{|c|}{$\begin{array}{l}\text { As viewed by children } \\
\qquad N=307\end{array}$} \\
\hline & $\begin{array}{l}\text { Less likely to } \\
\text { happen to me }\end{array}$ & $\begin{array}{l}\text { More likely to } \\
\text { happen to me }\end{array}$ & $\begin{array}{l}\text { Ratio of less to } \\
\text { more likely }\end{array}$ & $\begin{array}{l}\% \text { use of skill for } \\
\text { reduced personal } \\
\text { risk (among those } \\
\text { who regarded it } \\
\text { as less likely to } \\
\text { happen to them) }\end{array}$ \\
\hline Bike & $36.20 \%$ & $19.90 \%$ & $1.82^{\mathrm{c}}$ & $42.20 \%{ }^{\mathrm{c}}$ \\
\hline Trampoline & $44.20 \%$ & $20.65 \%$ & $2.14^{\mathrm{c}}$ & $6.80 \%{ }^{\mathrm{d}}$ \\
\hline Pedestrian & $53.10 \%$ & $3.30 \%$ & $16.09^{\mathrm{a}}$ & $76.30 \%^{\mathrm{a}}$ \\
\hline Dog bite & $57.37 \%$ & $12.40 \%$ & $4.63^{b}$ & $63.10 \%^{\mathrm{b}}$ \\
\hline Burns & $42.60 \%$ & $17.70 \%$ & $2.41^{\mathrm{c}}$ & $28.80 \%^{\mathrm{c}}$ \\
\hline Electrical & $78.30 \%$ & $4.59 \%$ & $17.06^{\mathrm{a}}$ & $37.80 \% \%^{\mathrm{c}}$ \\
\hline Drowning & $61.30 \%$ & $6.50 \%$ & $9.43^{\mathrm{a}}$ & $77.20 \% \%^{\mathrm{a}}$ \\
\hline Lightning & $63.90 \%$ & $5.20 \%$ & $12.29^{\mathrm{a}}$ & $33.50 \% \%^{\mathrm{c}}$ \\
\hline
\end{tabular}

$+\quad$ non-shared superscript indicates significant differences between values established via $x^{2}$ paired comparisons at $\mathrm{p}<.01$ 


\subsection{Children's optimism}

In response to being asked if the accident was 'same likelihood', 'less likely' or 'more likely' to happen to them, on average children gave 4 optimistic/less likely responses, $M=$ $4.38,95 \% C I[4.20,4.56] ; 1$ pessimistic/more likely response, $M=0.90,95 \% C I[0.79,1.02]$, and 3 same likelihood responses, $M=2.72,95 \% C I[2.56,2.87]$. Thus the most common response was to judge the accident as less likely to happen to the self than to others of the same age. However, the extent of children's optimism varied depending on the specific accident. Optimism was related to both true frequency $(r(6)=-.73, p=.040)$ and perceived frequency $(r(6)=-.81, p=.016)$. The three accidents with low frequencies are characterised by high levels of optimism. Optimism that the accident will not happen to the self in comparison to other children their age was expressed by $78 \%$ of children for electrical accidents, $64 \%$ for lightning, and $61 \%$ for near drowning. The four most dangerous accidents according to the children (pedestrian accidents, being struck by lightning, being electrocuted and drowning) were judged as significantly 'less likely to happen to me' than the less dangerous accidents (paired $t(306)=9.31, p<.001$ ). Table 2 shows the ratio between children reporting these accidents being 'less' and 'more likely to happen to me'. For the most dangerous four accidents, on average, the number of children regarding them as 'less likely to happen to me' is 13 times greater than the number of children who report that they are 'more likely to happen to me'.

When children report themselves as less likely to experience an accident than other children they either describe themselves as having the skills to mitigate the risk or they regard themselves as not exposed to risk, usually because they are 'not allowed' to do something or are otherwise protected by adult action (see Table 2). Among the high frequency accidents, pedestrian and trampoline accidents show different patterns of response. In the case of pedestrian accidents, children rarely think this accident is more likely to happen to them than 
to other children and references to skill account for $76 \%$ of the explanations given (e.g. 'I am very careful/ I have practiced crossing the road / I would always look'). This is in contrast to the relatively small number of children who refer to lack of opportunity/others' control of the environment, (e.g. having an adult with them when they cross the road). In the case of a trampoline accident, $44 \%$ thought it less likely to happen to them, but only $7 \%$ of them attributed this to their skill, with the remainder thinking they were not at risk due to adult control of the environment - such as 'we have a net around our trampoline'.

In the case of low frequency accidents (drowning, lightning), both show high levels of optimism but for different reasons. In the case of drowning, $77 \%$ of those claiming to be less likely to experience this accident referred to skills such as having done a life savers' course or being able to swim very well. In contrast, skill plays little part in children's explanation of why they are less likely to be struck by lightning than other children. Although $64 \%$ of children are optimistic, only $34 \%$ attribute not being struck by lightning to their own skill/knowledge and the remainder refer to parental control (such as 'not being allowed out in a storm').

\subsection{Risk availability}

In order to estimate the availability of the eight accidents the children were asked to pick an accident which they could feature in a thrilling and exciting story. $38 \%$ of children nominated a lightning accident, and 34\% nominated a drowning accident as being the accident which would help make a story dramatic. The only other accident to be nominated by more than $10 \%$ of children as dramatic was the pedestrian accident, nominated by $18 \%$. Those who nominated the pedestrian accident as dramatic were more likely to allocate more admissions to this kind of accident than did other children, and saw pedestrian accidents as similar in admission rate (16\%) as those due to bike (19\%) and trampoline (17\%) accidents, 
and higher than those due to dog-bite $(12 \%)$, paired $t(54)=2.51, p=.015, d=0.53$, or due to burn injuries accidents $(11 \%)$, paired $t(54)=3.39, p=.001, d=0.66$.

\subsection{Gender}

Since males are over-represented in accident figures in many domains (Fauth and Ellis, 2010) for each accident the frequency and danger judgment data were examined for gender differences and none were found. Nor were gender differences found on overall optimism (i.e. citation of 'less likely'/ 8 accidents: males $M=4.39,95 \% C I[4.11,4.66]$, females $M=4.37,95 \% C I[4.13,4.61], t(305)=0.10, p>.250$, or on use of skill as an explanation: males $M=1.87,95 \% C I[1.63,2.11]$, females $M=2.06,95 \% C I[1.81,2.29]$, $t(305)=1.06, p>.250$. See Supplementary Material Table S3 for details. The study was not able to include a measure of socio-economic status at an individual level.

\section{Discussion}

\subsection{Findings}

The study investigated whether children are subject to the same risk assessment biases shown by adults in previous research (qv. Lichtenstein et al., 1978). In reference to the eight accidents presented, children overestimated the frequencies of rare accidents/injuries and underestimated the frequencies of more common accident/injuries. As the two rarest injuries/accidents (being struck by lightning and near-drowning) were also nominated as the most 'thrilling and exciting' accidents, this lends credence to the proposition that the sensational aspect of an injury/accident plays a part in its availability and consequent overestimation (Lichtenstein et al, 1978). This is also supported by the fact that the children who 
nominated a pedestrian accident as dramatic and sensational were less subject than the rest of the children to underestimate its occurrence.

Children showed optimistic bias. Those estimating their own risk as less than their peers far outnumbered those who estimated their own risk as greater than their peers.

Children's explanations for why they are less likely to experience an accident in comparison to their peers provide insight into their ideas about accident causation. They justified their optimism by referring to their own skill or to others' control of their environment (e.g. 'I am not allowed to ride my bike on the road', or 'We haven't got any electrical sockets in the bathroom'). That the use of skill as an explanation varied by type of accident suggests its use was not primarily related to the need to present themselves as responsible to the adult researcher. Children's references to their own skills as a way in which they mitigate risk are evidence of their empowerment. However, this has the danger of potentially leading to a false sense of security. Pedestrian accidents have a high objective frequency and are accidents which children rate as dangerous, yet whose frequency children underestimate. Hospital admissions due to pedestrian accidents were judged by the majority of children as having the same frequency as dog-bite injury (despite being 3 times more common) and burn injury (despite being 6 times more common).

Trampoline accidents, which are increasingly common (Kasmire et al., 2016), are judged as the second most frequent accident and judged alongside dog-bite as being the least dangerous. Children who stated that this accident would be less likely to happen to them in comparison to their peers reasoned that it would not happen to them as 'they had a net around their trampoline'. Comments such as this illustrate two points. Firstly, they indicate that children think that falling off is the key danger, and do not appear to recognise other causes of trampoline injuries (Mulligan et al., 2016). In one survey of trampoline injuries presenting to a children's emergency department, $68 \%$ of the children sustained their injuries on the 
trampoline itself - for example by colliding either with other children using the trampoline at the same time and/or by impacting with the frame and springs within the safety net itself (Wootton and Harris, 2009). Secondly, they make clear that children are prompted to think about accidents in a real world context, beyond the specifics of the illustration.

\subsection{Limitations}

A limitation of this research is that it addressed children's perceptions of a restricted number of risks, although these eight risks accounted for one in five of coded hospital accident admissions for the age group. The study's strengths lie in its method, including two measures of frequency (one of which was innovative), and following Weinstein (2000), measuring both perceived probability and severity/danger. In addition, the absolute measure of frequency which involved assigning tokens to indicate frequency of accident types may have encouraged children to believe that they had to give one or more tokens to each type. However, $12 \%$ of the children did assign zero to one or more categories.

\section{Conclusion}

Frequency underestimation and optimism biases need to be addressed to enhance safety education. In this study children not only underestimated the likelihood of a pedestrian accident but this accident was also subject to one of the highest levels of assumed skill. Given the difficulty in reducing the power of optimism biases (Horswill et al., 2004), children not only need the skills current safety training develops, but also different skills. Risk awareness needs to be raised without incapacitating children by rendering them over-fearful (Witte and Allen, 2000). Instruction needs not only to teach routines, such as the Green Cross Code, but also alert children to circumstances in which they might be less skilful than they think they are, resulting in momentary abandonment of safe behaviour. Examples could include being in 
a hurry, talking on a mobile (Violano et al., 2015) or playing Pokémon Go. This potential loss of situational awareness may best be addressed by enhancing children's ability to monitor the execution of their risk-management skills (Schneider, 2008).

\section{Acknowledgements}

Thanks are due to The Royal Society for the Prevention of Accidents (RoSPA/BNFL Scholarship scheme) for funding. RoSPA have had no involvement in the study design, data collection and analysis, or in writing of the report. Thanks are also due to Kevin Watson, Public Health England for the provision of age specific Hospital Episode Statistics, to the Year 6 children and staff in 32 primary schools in Oxfordshire, and to Robert Duncan for art work.

\section{References}

Department of Health (2016) Reference Costs 2015-2016

https://www.gov.uk/government/publications/nhs-reference-costs-2015-to-2016

Fauth, R. \& Ellis, A. (2010). Reducing unintentional injuries in childhood: A research review. London: National Children's Bureau. http://www.ncb.org.uk/media/432942/childhood_unintentional_injuries review.pdf

Horswill, M.S., Waylen, A.E., \& Tofield, M.I. (2004). Drivers' ratings of different components of their own driving skill: A greater illusion of skill relating to accident involvement. Journal of Applied Social Psychology, 34(1), 177-195. doi: 10.1111/j.1559-1816.2004.tb02543.x

Jacobs, J. E., \& Klaczynski, P. A. (2002). The development of judgment and decision making during childhood and adolescence. Current Directions in Psychological Science, 11(4), 145-149. 
Kasmire, K. E., Rogers, S. C., \& Sturm, J. J. (2016). Trampoline park and home trampoline injuries. Pediatrics, 138(3) doi: 10.1542/peds.2016-1236

Lamb, R., Joshi, MS., Carter, W., Cowburn, G., \& Matthews, A. (2006). Children's acquisition and retention of safety skills: the Lifeskills program. Injury Prevention, 12: 161-165. http://dx.doi.org/10.1136/ip.2005.010769

Lichtenstein, S., Slovic, P., Fischhoff, B., Layman, M., \& Combs, B. (1978) Judged frequency of lethal events. Journal of Experimental Psychology: Human Learning and Memory, 4(6), 551-578. http://psycnet.apa.org/doi/10.1037/0278-7393.4.6.551

Lyons, RA., Kendrick, D., Towner, E.M., Christie, N., Macey, S., Coupland, C. \& Gabble, BJ. (2011). Measuring the population burden of injuries - implications for global and national estimates: A multi-centre prospective UK longitudinal study. PLoS Medicine, 8(12), e1001140. http://dx.doi.org/10.1371/journal.pmed.1001140

Miskin Group (2103) Childhood Injury in the UK - an Overview. http://www.miskingroup.org.uk/injury.htm

Mulligan, C.S., Adams, S. \& Brown, J. (2016) Paediatric injury from indoor trampoline centres. Injury Prevention, doi:10.1136/injuryprev-2016-042071

PACTS (2013). Stepping Out, Pedestrian Casualties: An analysis of the people and circumstances. Parliamentary Advisory Council for Transport Safety/ Road Safety Analysis

Public Health England (2014). Reducing unintentional injuries on the roads among children and young people under 25 years. London: Public Health England.

Schlottmann, A. \& Wilkening, F. (2012) Judgment and decision making in young children. In M.K. Dhami, A. Schlottmann, \& M.R. Waldmann (Eds.) Judgment and decision making as a skill. Cambridge: Cambridge University Press, pp 55-84. 
Schneider, W. (2008). The development of metacognitive knowledge in children and adolescents: Major trends and implications for education. Mind, Brain and Education, 2(3), 114-121. doi:10.1111/j.1751-228X.2008.00041.X

Schwebel, D. C., Combs, T., Rodriguez, D., Severson, J., \& Sisiopiku, V. (2016). Community-based pedestrian safety training in virtual reality: A pragmatic trial. Accident Analysis \& Prevention, 86, 9-15. http://dx.doi.org/10.1016/j.aap.2015.10.002

Schwebel, D.C., Davis, A.L., \& O’Neal, E.E. (2012). Child pedestrian injury: A review of behavioral risks and preventive strategies. American Journal of Lifestyle Medicine, 6(4), 292-302. doi: 10.1177/0885066611404876

Shaw, B., Watson, B., Frauendienst, B., Redecker, A., Jones, T., \& Hillman, M. (2013). Children's independent mobility: A comparative study in England and Germany (1971-2010). London: Policy Studies Institute. http://www.psi.org.uk/site/publication detail/852/

Sheeran, P., Harris, P. R., \& Epton, T. (2014). Does heightening risk appraisals change people's intentions and behavior? A meta-analysis of experimental studies. Psychological Bulletin, 140(2), 511-543. http://dx.doi.org/10.1037/a0033065

Shepperd, J.A., Klein, W.M.P., Waters, E.A., \& Weinstein, N.D. (2013). Taking stock of unrealistic optimism. Perspectives on Psychological Science, 8(4), 395-411. doi: $10.1177 / 1745691613485247$

Shepperd, J.A., Waters, E.A., Weinstein, N.D., \& Klein, W.M.P. (2015). A primer on unrealistic optimism Current Directions in Psychological Science, 24(3), 232-237. doi: $10.1177 / 0963721414568341$

Slovic, P. (1987). Perception of risk. Science, 236: 280-285. 
Taylor, E. (2015). RoSPA's priorities and the future of LASER. Data collected at 2 NHS Emergency departments 1/1/2012 - 30/3/2014, as presented to RoSPA/LASER springtime symposium, Cheshire Fire \& Rescue Service, 5 March 2015.

Towner, E., Dowswell, T., Errington, G., Burkes, M. \& Towner, J. (2005). Injuries in children aged 0-14 years and inequalities. London: NHS/Health Development Agency. http://eprints.uwe.ac.uk/2035

Tversky, A. \& Kahneman, D. (1973). Availability: A heuristic for judging frequency and probability. Cognitive Psychology, 5, 207-232. doi:10.1016/0010-0285(73)90033-9

Violano, P., Roney, L. \& Bechtel, K. (2015). The incidence of pedestrian distraction at urban intersections after implementation of a Streets Smart campaign. Injury Epidemiology, 2(18). doi: 10.1186/s40621-015-0050-7

Wann, J.P., Poulter, D.R., \& Purcell, C. (2011). Reduced sensitivity to visual looming inflates the risk posed by speeding vehicles when children try to cross the road. Psychological Science, 22(4), 429-434. doi: 10.1177/0956797611400917

Weinstein, N.D. (2000) Perceived probability, perceived severity, and health-protective behaviour. Health Psychology, 19(1), 65-74. http://dx.doi.org/10.1037/0278$\underline{6133.19 .1 .65}$

Whalen, C.K., Henker, B., O’Neil, R., Hollingshead, J., Holman, A., \& Moore, B. (1994). Optimism in children's judgments of health and environmental risks. Health Psychology, 13(4), 319-325. http://dx.doi.org/10.1037/0278-6133.13.4.319

White, M. J., Cunningham, L. C., \& Titchener, K. (2011). Young drivers' optimism bias for accident risk and driving skill: Accountability and insight experience manipulations. Accident Analysis \& Prevention, 43(4), 1309-1315.

http://dx.doi.org/10.1016/j.aap.2011.01.013

WHO (2008). World report on child injury prevention. Geneva: WHO/Unicef. 
Witte, K. \& Allen, M. (2000). A meta-analysis of fear appeals: implications for effective public health campaigns. Health Education \& Behavior, 27(5), 591-615. doi: $10.1177 / 109019810002700506$

Wootton, M. \& Harris, D. (2009). Trampolining injuries presenting to a children's emergency department. Emergency Medicine Journal, 20(6), 728-731.

doi:10.1136/emj.2008.069344 